\title{
What is the Future British Population?
}

WITH all the current excitement about the growth of population in the world, it is inevitable that great interest will attach to the second report of the Government Actuary giving population projections between 1971 and 2011 (HMSO, £1.00). The best news is that the Government Actuary now proposes to publish population projections once a year. The second cause for cheerfulness is that the projections now published are substantially less than those put out only a year ago. For the United Kingdom as a whole, the population in 2001 is now projected at 63.1 million, five per cent below the projection of a year ago. The projected increase of population between now and the end of the century is 7.4 million compared with the projected increase of 10.5 million a year ago. On the face of things, at least, the population projections seem to be moving in the right direction.

This is why it is important that too much should not be made of the projections now available. Predicting the growth of a population is a most hazardous exercise. One of the reasons for the difference between the projections made in 1971 and 1972 is that last year's census revealed that the population of the United Kingdom is 400,000 less than had been suggested by the accumulation of birth and death certificates since the previous census in 1961, no doubt because emigration from Britain had been under-estimated (which is why the new projections also assume that emigration in the years ahead will remove an extra 20,000 people each year from Britain). But the principal cause of the difference between the successive projections is that the experience of the past few years has compelled more modest assumptions about fertility. The hazard here for the demographers is that the observed reduction of fertility among married women may be a result of the postponement of child-bearing, not a sign that completed family size will eventually be correspondingly reduced. This is why the Government Actuary has made only a cautious revision of the estimates of average family size since the last set of projec-

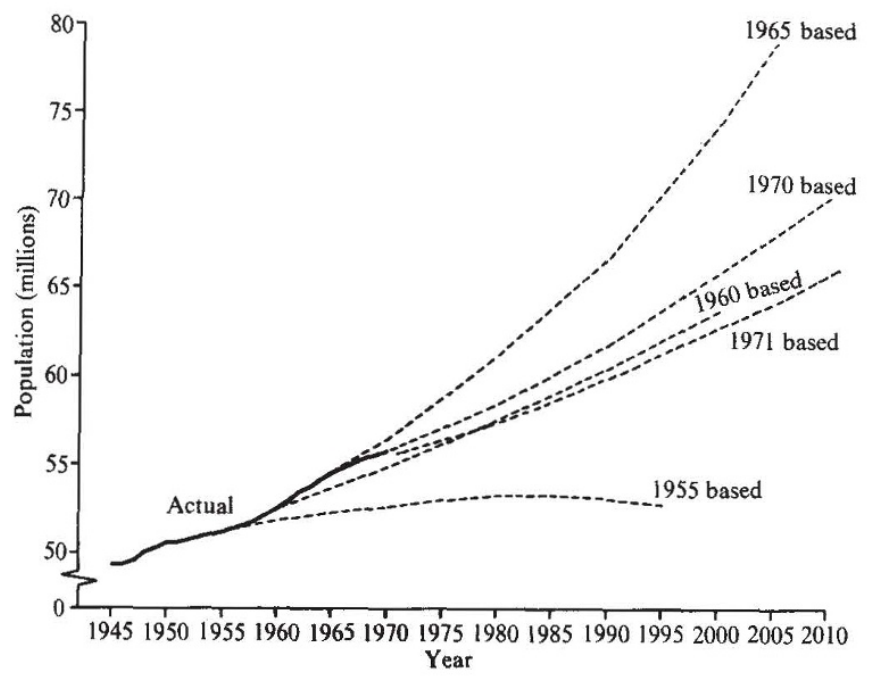

UK Population Projections 1955-71. tions - it is now assumed that women married or marrying in 1967 or later will on the average have 2.33 children, not 2.40 as was supposed a year ago.

It is plain that nobody should be surprised if future annual projections of the British population turn out to differ markedly from those now published. If the recent decline of fertility continues, or if events show that it leads to a completed family size significantly less than that on which the latest projections are based, the result could be a still further reduction of the projected population by the end of the century. It is by no means beyond the bounds of possibility that the increase of the British population in the next decade will turn out to be even less than the 3.6 per cent now projected. On the other hand, as the experience of the post-war decades has shown vividly enough, there is no assurance that fertility will not in future increase to the levels which obtained in the early 1960s. And now there is a new imponderable-how will British membership of the European Community affect international migration? There is at least a chance that the outward flow from Britain will be accelerated by the demands for labour in countries such as West Germany. It follows that regular readers of the Government Actuary's report should be prepared to be surprised.

What does the latest set of projections imply for that nebulous concept-a population policy? According to the projections now published, the number of children in the United Kingdom under the age of 15 will have decreased between 1971 and 1981, from 13.5 million to 13.4 million. In the same period, the number of adults of working age will have increased from 33.27 million to 34.6 million, while the number of those above retirement age will have increased proportionately still more rapidly, from 8.9 million to 9.7 million. On the present projections, the numbers of children in the population will begin to increase substantially only in the late 1980 s, as the children born in the 1960 s reach childbearing age (and this is the part of the projection most likely to be falsified if recent fertility trends continue). It follows that for the next decade at least, the most burdensome demographic trend will be the increase of about 12 per cent in the numbers of people in retirement, but the growth of the working population should in strictly economic terms be partially a recompense. It follows that those who would seek to stabilize the British population would be well advised to concentrate their attention on the young people still at school who are the potential parents of the 1980s. Is it beyond the wit of what is after all a sophisticated educational system to devise educationally acceptable courses of instruction that will bring home to young people the importance to them as individuals, and not merely the convenience to the nation as a whole, of trying to ensure that the number of children at school in the 1980 s is not very different from what it is at present? But then, again as a matter of personal liberty, there is a case for a still more urgent development of family planning services, abortion on demand included. 